\title{
Seismic Isolation of Offshore Pipeline Block Valve Stations
}

\author{
Liudmila Muravieva ${ }^{1, *}$ \\ ${ }^{1}$ Peter the Great Saint-Petersburg Polytechnic University, 195251 Polytechnicheskaya str. 29, St. \\ Petersburg, Russia
}

\begin{abstract}
As shown by the actual material analysis of offshore pipeline damage caused by strong earthquakes, the greatest damage is caused to complex assemblies such as branch connections, bends, and various joints .In the seismic resistance analysis of the offshore pipeline a fixed junction of an offshore pipeline section with a block valve station is modeled. To assess the connection assembly for seismic resistance, a number of accelerograms with descriptions of magnitude 8 and 9 earthquakes in the Black Sea region were considered. The calculations have revealed significant pipe wall stresses in the offshore pipeline/block valve station junction. The resulting conclusion is that offshore pipeline block valve.
\end{abstract}

\section{Introduction}

Researches M.J O'Rourke and Sh.G. Napetvaridze mention that failure rate of the trunk pipelines increases at the points of connection to the equipment. Seismic resistance of the connections/block valve stations of the buried onshore pipeline is reviewed in the studies of T.R. Rashidov and G.Kh. Khozhmetov.

Calculations of the seismic loads on the linear sections of the pipeline are described in the regulatory documents of STO Gazprom [12], and on the offshore pipeline in the Maritime Register Guidance NDN2-020301-003 [8].

The characteristic feature of the offshore pipelines is that they have only two block valve stations. To control impact of deformations caused by process loads when designing offshore pipelines, pipe bends are used.

Vibration protection issues are addressed in the Manual (RD). It is required that «maximum allowable vibration amplitude of the process pipelines shall be $0.2 \mathrm{~mm}$ at a maximum vibration frequency of $40 \mathrm{~Hz} »[9]$.

The analysis shows that the detailed seismic resistance study of the offshore pipeline fittings (block valve stations/shutoff valves) shall be further conducted.

\section{Landfall section of pipeline}

The paper deals with vibration protection of block valve stations /shutoff valves of the offshore pipeline, and includes the trunk pipeline design scheme made with due regard for

\footnotetext{
* Corresponding author: rfludmia@yandex.ru
} 
damper/elastic supports. Vibration isolation of the offshore pipeline block valve station is also analyzed.

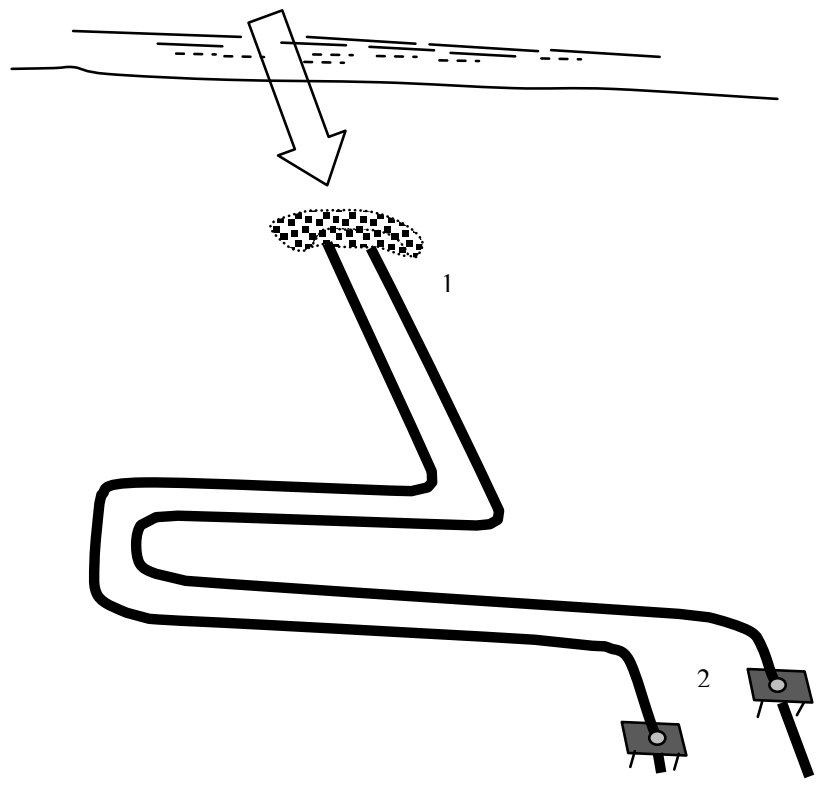

Fig.1. Landfall section of pipeline onshore landfall diagram, 1 - Gas pipelines laid on the seabed have landfall where the shutoff valves 2 are installed, 2 - Ball valves to isolate gas flow.

\subsection{Seismic resistance analysis of the offshore pipeline}

\subsubsection{Calculation between the offshore pipeline section and block valve station}

In the seismic resistance analysis of the offshore pipeline (7) a fixed connection between an offshore pipeline section and block valve station is modeled. A number of accelerograms with descriptions of magnitude 7 and 9 earthquakes in the Black Sea and Caspian Sea are considered.

The calculations have revealed significant pipe wall stresses at the connection point between the offshore pipeline section and block valve station. The resulting conclusion is that offshore pipeline block valve stations need to be equipped with dampers.

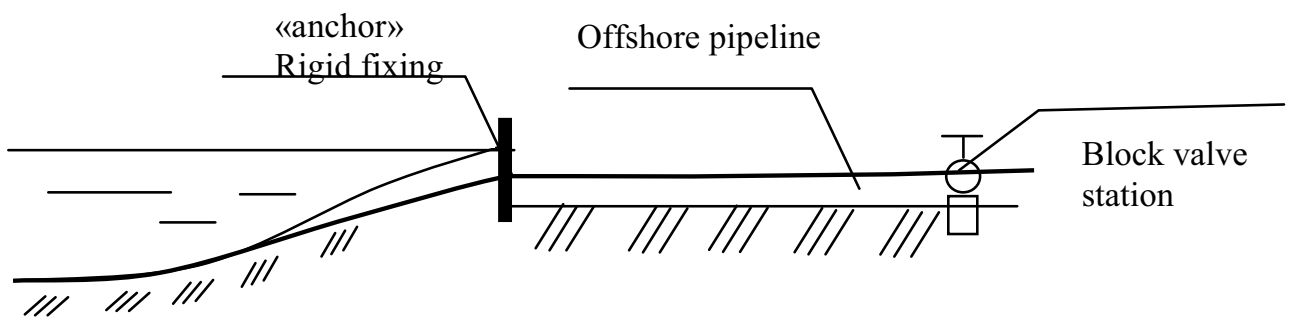

Fig.2. Landfall section of pipeline block valve station. 


\subsubsection{Seismic resistance analysis of the offshore pipelines}

In the course of seismic resistance analysis of the offshore pipelines level of stresses and allowable deformations of the pipe walls are evaluated. Pipe bends are installed to account for the deformations caused by workloads in the offshore pipelines.

Each seismic wave gives earth shocks to buildings. Destructive earthquakes with magnitude of 8 or 9 are characterized by pulse propagation. For example in the northern part of the Izu peninsula (Japan) seismic pulse of 0.015 to $0.12 \mathrm{~m} / \mathrm{s}$ repeated 18 times within 55 seconds. In this paper vibration isolation of the offshore pipeline block valve station has been analyzed.

Change in object vibrations from external dynamic loads can be done by different methods: vibration scattering and redistribution of vibration energy. The first case refers to inertial dynamic dampers that are mainly used to suppress monoharmonic or narrow-band random vibrations. In the event of wide-band vibrations it is preferred to connect additional damping elements to an object such as absorbers.

\subsection{Equation of the protected object motion}

Differential equation of the protected object motion is represented as follows:

$$
m \ddot{u}+c_{0} \dot{u}+f(\dot{u}, u)=-m \ddot{u} g
$$

More accurate solutions are observed if behavior of dampers is taken into account. This leads to solving of the nonlinear task. Differential equation of the object motion with consideration of dampers is represented as follows:

$$
\ddot{u}+2 \omega_{0}\left(\xi+\xi_{e q}\right) \dot{u}+\omega_{0}^{2}=-\ddot{u} g
$$

A constant section beam with various end fixings (with one end fixed and the other end semi-fixed relative to angular movement and fixed end relative to transverse movement) is taken as a design model for the offshore pipeline with block valve station. Impacts of shear loads and inertia of cross section are not taken into consideration.

Differential equation of natural bending vibrations of this beam is represented as follows:

$$
E I \frac{\partial^{4} y(x, t)}{\partial x^{4}}+m \frac{\partial^{2}(x, t)}{\partial t^{2}}=0
$$

where $\mathrm{y}(\mathrm{x}, \mathrm{t})$ is beam deflection.

By introducing $\bar{x}=x / l$ as an independent variable, where 1 is a beam length, we form the differential equation (3) as follows:

$$
\frac{d^{4} f(\widetilde{x})}{\partial x^{4}}-\alpha^{4} f(x)=0
$$

here $\alpha^{4}=p^{2} \frac{m l^{4}}{E I} ; \mathrm{p}$ is a cyclic frequency of natural vibration, $\mathrm{f}(\mathrm{x})$ is a shape function of bending vibrations of the beam.

General solution of the equation (3) is written in the following form: 


$$
f(x)=A S(\alpha x)+B T(\alpha x)+C U(\alpha x)+D V(\alpha x)
$$

where A,B,C and D are arbitrary constants determined from corresponding boundary conditions, $S(\alpha x), T(\alpha x), U(\alpha x)$ and $V(\alpha x)$ are linear combinations of circular and hyperbolic functions introduced by A.N. Krylov [6].

We assume the design model of the linear section of the pipeline with block valve station as a beam which has one end fixed and the other end elastically restrained against angular movement and fixed against transverse movement (Fig. 3)

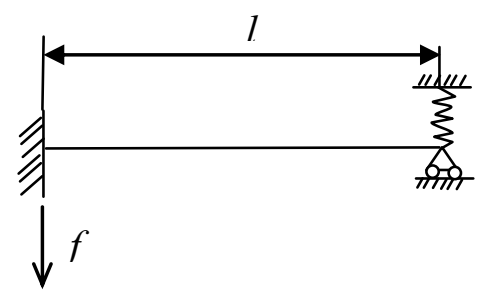

Fig. 3. A beam with one end fixed and the other end elastically restrained against angular movement and fixed against transverse movement.

Boundary conditions are written as follows:

$$
\begin{aligned}
& \text { - at } \bar{x}=0: f(0)=0 ; f^{\prime}(0)=0 ; \\
& \text { at } \widetilde{x}=l \quad f(l)=0 ; f^{\prime}(l)=-\frac{h l}{F I} f^{\prime}(l)
\end{aligned}
$$

By applying boundary conditions to the functions $f(\bar{x})_{\text {И }} f^{\prime}(\bar{x})$ at $x=0$ we define A and $B$ values.

$$
\begin{aligned}
& f(\bar{x})=A S(\alpha \bar{x})+B T(\alpha \bar{x})+C U(\alpha \bar{x})+D V(\alpha \bar{x}) \\
& f^{\prime}(x)=\frac{\alpha}{l}[A V(\alpha x)+B S(\alpha x)+C T(\alpha x)+D U(\alpha x)]
\end{aligned}
$$

The result is the following: $A=0$ and $B=0$.

With an account of the boundary conditions to the function $\mathrm{f}(\bar{X})$ and its derivatives ' $(\bar{X})$ and $\mathrm{f}^{\prime \prime}(\bar{X})$ at $\bar{X}=1$, we obtain the following system of homogeneous equations:

$$
\begin{gathered}
C U(\alpha)+D V(\alpha)=0 \\
C[\alpha S(\alpha)+\hbar T(\alpha)]+D[\alpha T(\alpha)+\hbar U(\alpha)]=0
\end{gathered}
$$

where $\bar{h}=\frac{h l}{E I}$ is a relative rigidity of anchorage. 


\section{Frequency equation of the bending vibrations of the beam}

By equating a system determinant (6) to zero we obtain the following frequency equation of the bending vibrations of the beam:

$$
U(\alpha)[\alpha T(\alpha)+\bar{h} U(\alpha)]-V(\alpha)[\alpha S(\alpha)+\bar{h} T(\alpha)]=0
$$

We determine the relation between root $\alpha$ of transcendent frequency equation and relative rigidity of anchorage $\bar{h}=\frac{l}{E I}$ based on recommendations $[1,6]$.

Frequency of beam vibration with due account for $\alpha$ is determined from the following formula:

$$
\omega=\frac{1}{2 \pi} \cdot \frac{\alpha^{2}}{l^{2}} \sqrt{\frac{E I}{m}}
$$

We suggest that vibrations of the linear section of the pipeline equipped with a block valve station can be damped with the help of an element (vibration isolation) containing elastic members.

We use vibration isolators made from rubber Grade 3311 and dynamic modulus of elasticity of vibration isolator made from rubber $E_{D}=250 \mathrm{~N} / \mathrm{cm}^{2}$ for vibration isolation of the block valve station. We assume height of the deformed part of the vibration isolators as $H_{p}=3 \mathrm{~cm}$ and cross section of the deformed part of the vibration isolator as $S_{i}=14.4$ (Fig.1).

Rigidity of the rubber vibration isolators can be calculated from the formula [8], where isolator rigidity is $\mathrm{K}=11213 \mathrm{~N} / \mathrm{cm}^{2}$, Relative rigidity of the elastic anchorage is $\bar{h}=52.8$ MPa.

$\hbar=h \frac{l}{E_{D} l}$, where $E_{D}$ is a dynamic rubber modulus and I is a moment of inertia of the isolator.
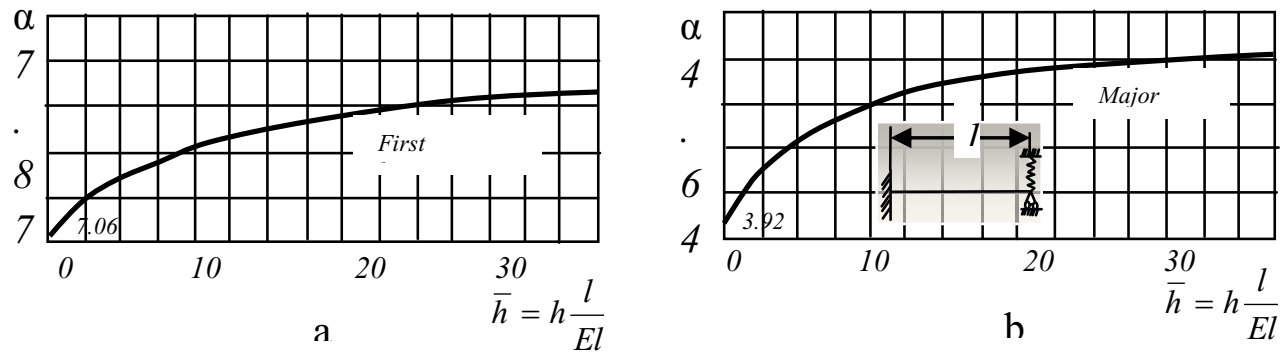

Fig. 4. Relation between root $\alpha$ of transcendent frequency equation and relative rigidity of anchorage $\bar{h}=h \frac{l}{E l}$ for the first harmonics (a) and major pitch (b).

From the curves on the Fig.4 [3] and $h$ we define root $\alpha$ of the transcendent frequency equation for the first harmonics, root $\alpha$ value for the first harmonics is $\alpha=7.0685$ (Fig.4a) and for the main pitch $\alpha=3.9266$ (Fig.4b).

In practice the effectiveness of the dampers is precisely characterized by equivalent viscous friction. 
Natural frequency of the offshore pipeline is determined as per formulas [6,7]. Damping properties of the offshore pipeline are characterized by damping coefficient $\xi$. Force acting on foundation and block valve station is determined by the deformation of the vibration isolator located between them.

According to [21], the following damping coefficients are adopted; damping coefficient of the pipeline design without concrete coating is $\xi$ st $=0.005$; damping coefficient of the soil foundation in the vertical direction is $\xi_{\mathrm{V}}=0.026$; rigidity coefficient of the soil foundation is $c_{1}=230.925 \mathrm{t} / \mathrm{m}^{3}$ [7]. Non-elastic resistance coefficient of the rubber vibration isolator is $v=0.038$.

\subsection{Vibration isolator}

Vibration isolator is intended to reduce force $\mathrm{R}(\mathrm{t})$ generated by the vibration isolator and transmitted to the fixed foundation.

In accordance with [4] design seismic force FE, u,is calculated, taking into account seismic hazard of the pipeline construction area, earth movement rate during earthquakes and design foundation response spectral ordinates.

\subsection{Deformation rate of the vibration isolator}

In case of force action force $\mathrm{R}(\mathrm{t})$ shall be determined by deformation and deformation rate of the vibration isolator, coordinates y and $\dot{y}$ :

$$
R(t)=k \dot{y}+c y
$$

Equation of mass movement $m$ may be written as

$$
m \ddot{y}+k \dot{y}+c y=F(t)
$$

Considering that all variables of the equation (10) vary per the harmonic law, $F(t)=$ $F_{0} e^{j w t}, R(t)=R_{0} e^{j w t}, y(t)=Y_{0} e^{j w t}$ we obtain a relation to determine amplitude of forced mass oscillations $m$;

$$
Y_{0}=\frac{F_{0}}{c} \sqrt{\frac{1+4 \xi^{2} \bar{\omega}^{2}}{\left[\left(1-\bar{\omega}^{2}\right)\left(C-\mu \bar{\omega}^{2}\right)-\bar{\omega}^{2}\right]^{2}+4 \xi^{2} \bar{\omega}^{2}\left[C-\bar{\omega}^{2}(1+\mu)\right]^{2}}}
$$

where $\bar{\omega}=\omega / \omega_{0}$ a is relative frequency of "pipeline +block valve station" system (of linear section of the pipeline with block valve station), $\omega_{0}$ is a natural frequency of the pipeline, $c_{1}$ is rigidity coefficient of the soil foundation of the block valve station $c_{\mathrm{rp}}=\mathrm{c}_{1}$ $\mathrm{N} / \mathrm{m}^{3}$ and damping coefficients of "pipeline+block valve station" system: $\xi=\xi_{\text {str }}+\nu+\xi_{\text {гр }}$ [7].

\subsection{Force $\mathbf{R}_{0}$, acting on the foundation}

We assume seismic vibration model described by V.V. Bolotin. Pursuant V.V. Bolotin we approximate non-stationary random function of seismic acceleration as a product of nonrandom envelope $A_{0} e^{-\gamma t}$ and stationary random function $\tilde{X}_{0}(t)$. Within this system oscillations are induced by seismic vibrations of the foundation that vary per the harmonic law $x(t)=X_{0} e^{j w t}$.

Coordinates of object vibration $y$ vary per the law $y(t)=Y_{0} e^{j w t}$. 
Irrespective of the excitation mode and damping value to ensure vibration protection for amplitude of force $R_{0}$, acting on the foundation, the following expression is used,

$$
R_{0}=\frac{F_{0} \sqrt{1+4 \xi^{2} \varpi^{2}}}{\sqrt{\left(1-\varpi^{2}\right)^{2}+4 \xi^{2} \varpi^{2}}}=\frac{F_{0} \sqrt{1+\eta^{2}}}{\sqrt{\left(1-\varpi^{2}\right)^{2}+\eta^{2}}}
$$

We calculate movement amplitude $\mu$ based on the allowable amplitude of foundation displacement $Y_{D}$ :

$$
\mu=\frac{\frac{F_{0}}{\left(c Y_{D}\right)}+1+(1+C)\left(\varpi^{2}-1\right)}{\varpi^{2}\left(\varpi^{2}-1\right)}
$$

Amplitude of movement is $\mu=2.85$.

Analysis of various damper types shows that:

- disadvantage of dry friction damper is wear of its mating surfaces which results in potential misalignment and jamming and causes damper failures.

- inconsistent viscous properties of oil due to temperature change causing damper detuning can be considered a problem of many viscous friction dampers.

Calculations of rubber vibration isolator impact on vibration amplitude of the block valve station have been made for the pipeline of the following size: diameter $350 \mathrm{~mm}$, weight $0.148 \mathrm{t} / \mathrm{m}$, coefficient of subgrade reaction is $c_{g r}=230.925 \mathrm{t} / \mathrm{m}^{3}$. Design span length of the pipeline section is $45 \mathrm{~m}$ [7].

\section{Amplitude of forced vibration}

Natural vibration frequency of the linear section of the pipeline present in table 1.

Frequency of the linear section of the pipeline. Table 1.

\begin{tabular}{|c|c|}
\hline Sr. No & $\omega(l)$ \\
& Frequency, $\mathrm{c}^{-1}$ \\
\hline 1 & with rigid fixing \\
& $=5.018$ \\
\hline
\end{tabular}

Seismic force equals to $F_{0}=0.464 \mathrm{H}[4,7]$.

Amplitude of forced vibration (of block valve assembly) of mass will be equal to $Y_{0}=0.686 \mathrm{~m}\left(c_{g r}=2 \mathrm{t} / \mathrm{m}^{3}\right)$, amplitude of force $R_{0}$, acting on the foundation is $1.008 \mathrm{t}$.

Study of vibration amplitude variation depending on foundation rigidity.

Force $F_{0}$ and allowable amplitude of foundation displacement $\mathbf{Y}_{\mathbf{D}}$ present in table 2 .

Force $F_{0}$ and amplitude of foundation displacement $\mathbf{Y}_{\mathbf{D}}$ Table 2.

\begin{tabular}{|c|c|c|}
\hline $\mathbf{C}_{\text {onp }}, \mathbf{t} / \mathbf{m}^{\mathbf{3}}$ & $\mathbf{R}_{\mathbf{0}}, \mathbf{t}$ & $\mathbf{Y}_{\mathbf{D}}, \mathbf{m}$ \\
\hline 230.925 & 1.008 & 14.334 \\
\hline 2 & 1.008 & 0.686 \\
\hline
\end{tabular}




\section{Conclusions}

Calculated $\mathrm{R}$ and $\mathrm{Y}$ values show insufficient vibration isolation when using only rubber elements. Vibration amplitude of "pipeline+block valve station" system exceeds the required value specified in [10]. Vibration isolation is ensured as a result of combination of mechanical and hydraulic elements. This solution requires installation of hydraulic mount (Fig.5).

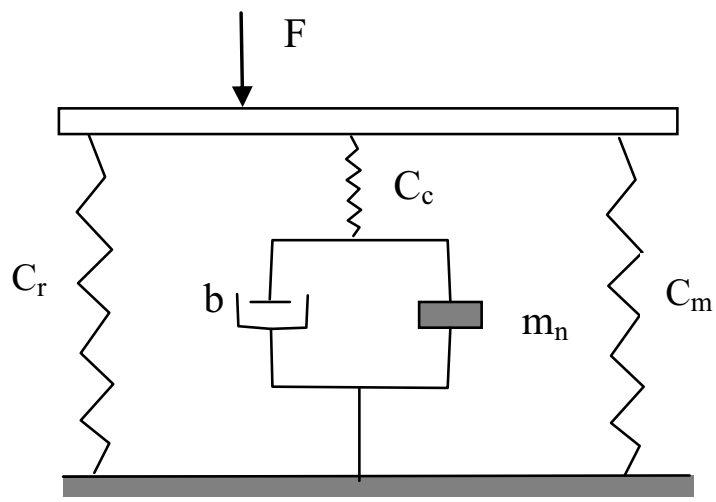

Fig.5. Schematic diagram of the hydraulic mount elastic element.

Vibration isolation of the block valve station of the offshore pipeline can be ensured by hydraulic mount installation. Vibration isolation is made based on interaction of mechanical and hydraulic sub-systems. Mechanical part interrelates with hydraulic part through equivalent resistance $C_{r}$, and hydraulic part interrelates with mechanical part through equivalent resistance $C_{M}$.

\section{References}

1. B.L. Bidermann. Vibrations and Impact Loads, In: Strength Calculation in Machine Engineering (Mashgiz, Moscow, 1959)

2. I.A.Birger, Bar Tension and Bending, Strength and Stability of Vibrations (M. «Mashinostroenie», Moscow, 1968)

3. ISO 3010 Basis for Design of Structures - Seismic Actions on Structures. International Standard, Second Revision (2001)

4. R. Klaff, G. Pensien, Structure and Dynamics (Stroyizdat, Moscow, 1979)

5. V.A. Kisilev, Structural Theory, Special Course (Stroyizdat, Moscow, 1980)

6. K. Magnus, Vibrations (Mir, Moscow, 1982)

7. Report on Contract No. PC-13/2015/203-03503. "Development of Seismic Resistance Requirements to Damaged Steel Offshore Pipelines" (2015)

8. Register's Rules for Classification and Construction of Subsea Offshore Pipelines. HDN2-020301-003: Russian Maritime Register of Shipping, Saint Petersburg: Russian Maritime Register of Shipping (2012)

9. RD 51-3-96 Regulation for Maintenance of Submerged Gas Trunkline Crossings through Water Barriers (JSC "Giprorechtrans, 1996)

10. Design Guideline for Vibration Isolation of Machines and Equipment (Stroyizdat, Moscow, 1972)

11. B.G. Korenev, I.M. Rabinovich, Guidelines for Structural Dynamics (Stroyizdat, Moscow, 1972) 
12. Equipment Produced by GERB, Information on http://www.gerbvibra.spb.ru/vibfo.html.

13. STO Gazporm 2-2.1-249-2008 Gas Trunklines

14. D.E. Chegodaev, Yu.K. Ponomarev. Damping (SSAU Publ., Samara, 1997)

15. S. H. Crandall, W. D. Mark. Random Vibration in Mechanical Systems (Academic Press, Moscow, 1963)

16. J. P. Den Hartog, Mechanical Vibrations, 4th Edition (Dover, 1985)

17. N. M. Newmark, E. Rosenblueth, Fundamental of Earthquake Engineering (Prentice Hall, London, 1971)

18. J. Ormondroyd, J. P. Den Hartog, Trans. ASME, J. of Applied Mechanics (1928)

19. A. Preumon, Vibration Control of Active Structures, Introduction, 3rd Edition (Springer, London, 2011)

20. A. Preumont, K. Seto, Active Control of Structures (Wiley, London, 2008)

21. B. F. Jr. Spencer, M. k. Sain, Special Issue of IEEE Control Systems Magazine on Emerging Technology, 17(6), 19-35, (1997)

22. Recommended Practice DNV-RP-F105 “Free Spanning Pipelines"(2002)

23. G. B. Warburton, Earthquake Engineering and Structural Dynamics, 10, 381-401 (1982) 